\title{
Phase Balancing by Means of Electric Vehicles Single-Phase Connection Shifting in a Low Voltage Danish Grid
}

\author{
Lico, Pasqualino; Marinelli, Mattia; Knezovic, Katarina; Grillo, Samuele
}

Published in:

Proceedings of the 50th International Universities Power Engineering Conference 2015

Link to article, DOI:

10.1109/UPEC.2015.7339967

Publication date:

2015

Document Version

Peer reviewed version

Link back to DTU Orbit

Citation (APA):

Lico, P., Marinelli, M., Knezovic, K., \& Grillo, S. (2015). Phase Balancing by Means of Electric Vehicles SinglePhase Connection Shifting in a Low Voltage Danish Grid. In Proceedings of the 50th International Universities Power Engineering Conference 2015 IEEE. https://doi.org/10.1109/UPEC.2015.7339967

\section{General rights}

Copyright and moral rights for the publications made accessible in the public portal are retained by the authors and/or other copyright owners and it is a condition of accessing publications that users recognise and abide by the legal requirements associated with these rights.

- Users may download and print one copy of any publication from the public portal for the purpose of private study or research.

- You may not further distribute the material or use it for any profit-making activity or commercial gain

- You may freely distribute the URL identifying the publication in the public portal 


\title{
Phase Balancing by Means of Electric Vehicles Single-Phase Connection Shifting in a Low Voltage Danish Grid
}

\author{
Pasqualino Lico*, Mattia Marinelli**, Katarina Knezoviće* and Samuele Grillo* \\ *Politecnico di Milano - DEIB \\ piazza L. da Vinci 32, 20133 Milano, Italy \\ Email: \{pasqualino.lico, samuele.grillo\} @polimi.it \\ ** Department of Electrical Engineering (Center for Electric Power and Energy) \\ DTU - Technical University of Denmark \\ Email: \{matm, kknez\}@elektro.dtu.dk
}

\begin{abstract}
In Denmark, household consumers are supplied with three phase with neutral cable. In addition, the distribution service operator cannot decide to which phase electrical appliance are connected. The technician who realizes the installation connects the loads according to his technical expertise. This may results in heavy imbalances. This paper uses a real Danish distribution system with household consumers, photovoltaic installation and electrical vehicles (EV). In this paper the possibility to use EVs' charging spots in order to reduce grid's imbalances will be investigated. Usually, charging stations are equipped with single-phase converters. According to the designed control strategy, the charging spot can select the phase to be used for the charge. The selection is done according to a phase voltage measurement.
\end{abstract}

Index Terms-Distribution network, electric vehicles, power system modeling, imbalance power system.

\section{INTRODUCTION}

Three-phase connection in Denmark is dominant also for residential customer, unlike in other European countries. Distribution system operators (DSOs) cannot decide which kind of appliances will be connected to the different phases and the choice is always left to the technician who realizes the electrical installation. Therefore, it may happen that in certain areas, all houses have the same appliances connected in the same phase. This may lead to a high degree of load imbalance, where typically one phase can get close to $50 \%$ of the overall power flow. For this reason, power systems can be heavily imbalanced [1], [2]. Electric vehicles (EVs) can be a suitable candidate for compensating these imbalances: several manufactures are providing EVs with domestic single phase chargers rated either $10 \mathrm{~A}$ or $16 \mathrm{~A}$ (i.e., $2.3 \mathrm{~kW}$ or $3.7 \mathrm{~kW}$ ), which if not properly coordinated, can lead to increased imbalance. A moderate penetration scenario from Danish Energy Association estimates that 47,000 EVs will be present in Denmark by 2020 [3]. The purpose of this paper is to present an approach to EVs' charge, which aims at reducing load imbalance and supporting voltage levels. The paper focuses on analyzing a real case for the potential future voltage support function by EVs. The paper is structured as follows. Section II is devoted to the definition of the designed control strategy for EVs' charging spots. In Section III the grid used for the simulation will be presented and analyzed, along with the main hypotheses used for the testing of the algorithm effectiveness. Simulations have been performed using DigSilent-PowerFactory [4]. In Sections IV the results for the selected scenarios are displayed and, finally, in Section V conclusions are drawn.

\section{Methodology}

The proposed control strategy is based on enabling the possibility of each charging spot to select the phase used for the recharge [5]. The first step is to perform a phase-to-neutral voltage measurement for each of the three phases, when the vehicle is plugged in. Then the controller moves the contact to the phase where the voltage is the highest and the charge can start. During the vehicle recharge, the contact are not allowed to change the phase until the charge is complete. In fact, the continuous phase update has to be prevented in order to avoid oscillations. In addition, a continuous phase update imply a continuous tripping operation and therefore, the contacts have to be oversized with respect to the case of a normal operation under off-load conditions. Another situation that has to be prevent is the simultaneous access of multiple vehicles present on the same grid's branch. This situation has been avoided by assigning an intra-day scheduling to each vehicle. According to this method, each vehicle can start the charge only when the assigned timestamp is reached. In order to make this technique commercially acceptable, four timestamps per hour have been assigned to each charging spot. Therefore, the maximum delay between the plug-in and charging start is 15 minutes. Figure 1 reports the control strategy flow chart. The charge starts after a time control and the power starts to flow only after the phaseselection. This implies that the contacts do not have to be oversized, as in the case of continuous update. In conclusion, according to this technique each charging spot configures the phase where to charge according to a real time estimation providing a balancing action. 


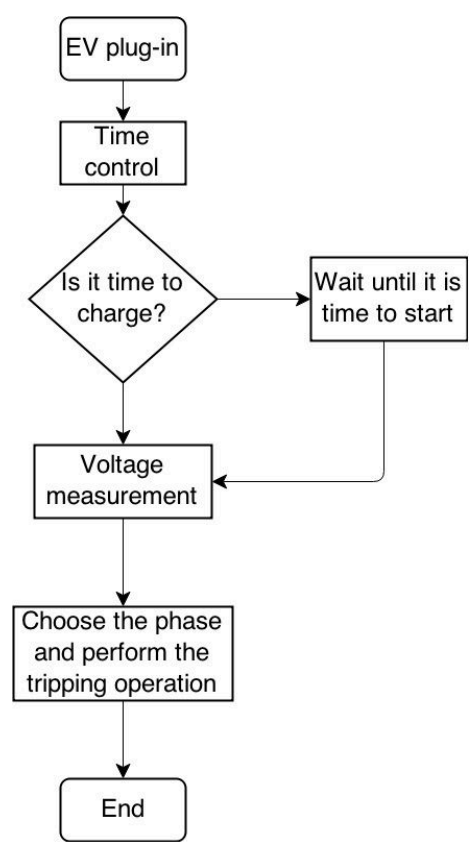

Figure 1. Control strategy flow chart.

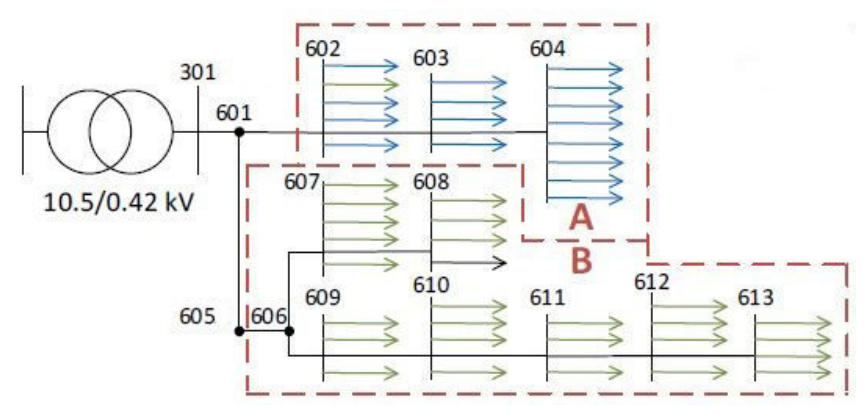

Figure 2. Observed low voltage grid.

\section{CASE Study}

The control has been testes on a grid reported in Figure 2. The observed low-voltage grid is composed of two streets, where 43 household consumers are located. The whole grid is divided into three parts coinciding with physical streets where the households are located, and is operated in radial configuration. The external grid short circuit power has been assumed equal to 20MVA and the grid's time acceleration constant equal to infinite. Therefore, no frequency control has been provided. The transformer has a rated power of $400 \mathrm{kVA}$ with a nominal ratio of $10.5 / 0.42 \mathrm{kV}$ and a short circuit voltage of $1 \%$. Part $\mathrm{A}$ in Figure 2 represents 17 houses located in Hørmarken Street while part B represents 26 households located in Græsmarken Street. In addition, a street light installation is connected at node 608. The distribution is composed of three phase plus a neutral which is directly grounded in the transformer's low voltage side. The two streets have two main differences. First, in Hørmarken Street only one consumers is equipped with a PV, in node 602 , whereas in
Græsmarken Street all the household consumers are equipped with PVs. Secondly, Hørmarken consumers use district heating whereas all the Græsmarken consumers use heating pumps. This causes substantial difference in consumption between the two streets during the winter season. Household consumption has been measured from January 2012 to March 2013. This paper analyses two days of the whole measurement due to computational time. The first selected day is Wednesday from the second week of January which is the one with the highest household consumption and the lowest PV production. It represents the worst integration case due to the low voltage magnitude caused by the high consumption. The second selected day is Wednesday from the third week of May, i.e., the day with the lowest consumption and the highest PV production. It represents the best integration case due to the high voltage magnitude cause by low consumption. Figure 4 reports the whole test grid consumption profiles in the two selected days. As it is possible to note, during the winter scenario the mean of the total consumption is between 4 and 5 times higher than the one in the spring scenario. Therefore, in order to simulate an imbalance and real situation phase A has been loaded with the $50 \%$ of the overall measure power whereas phases $\mathrm{B}$ and $\mathrm{C}$ with the $25 \%$ respectively. However, the power factor has been assumed equal to 0.95 ,

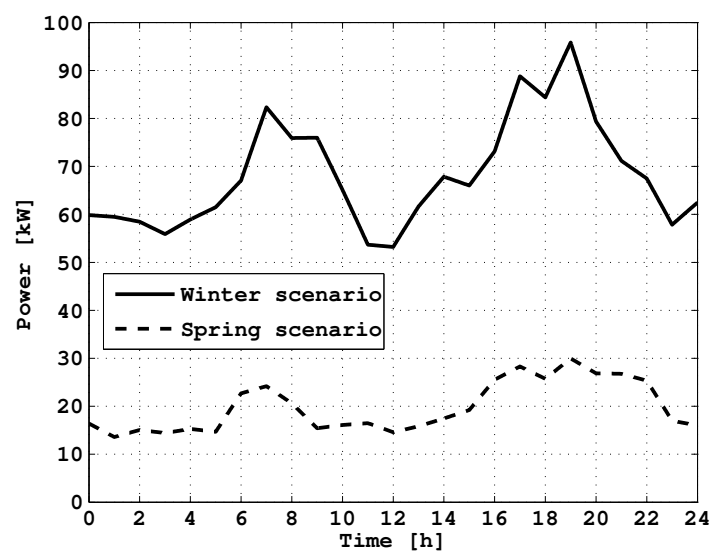

Figure 4. Consumption profiles during the winter and the spring scenarios.

which, in Denmark, is the minimum required for household consumers. PV installations use a single-phase inverter but the phase where they are connected is unknown. Therefore, the installations have been connected randomly in order to balance the overall power injection among the three phases. In the observed grid, $27 \mathrm{PV}$ installations are present. Each of the 26 household consumers in Græsmarken has a PV, 22 PVs have a rated power of about $2.3 \mathrm{~kW}$ whereas 4 of those have a rated power equal to $3.7 \mathrm{~kW}$ and are all located in node 613 . In Hørmarken is present only one PV with a rated power of $2.7 \mathrm{~kW}$. According to what has been done in [6] and [7] all $\mathrm{PVs}$ have been equipped with reactive power control (RPC). The control has been inspired by the Italian Standard CEI021 [8]. According to this RPC, PVs can participate in voltage 


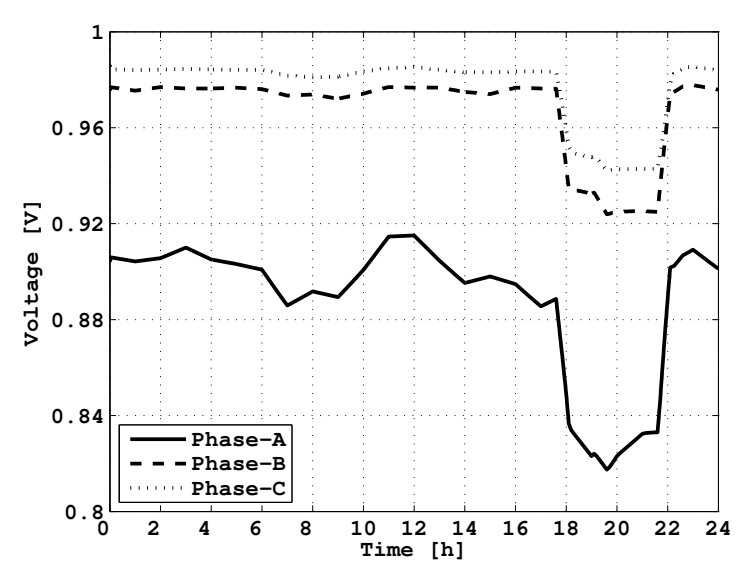

(a)

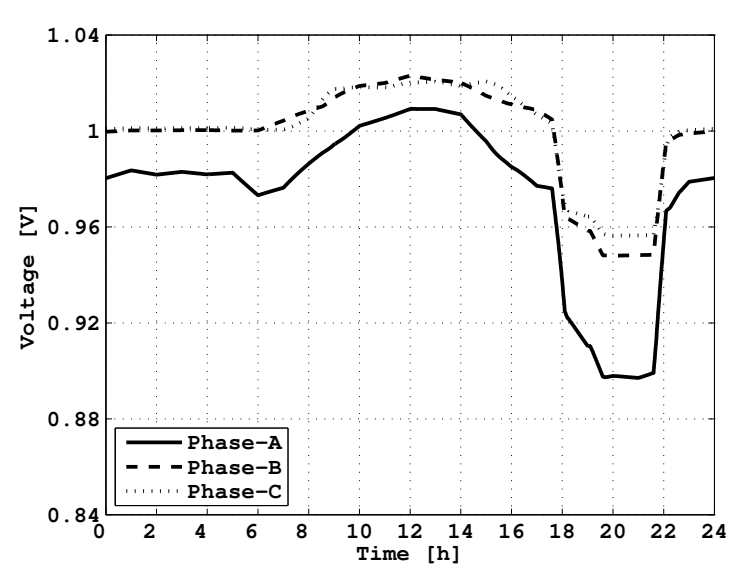

(c)

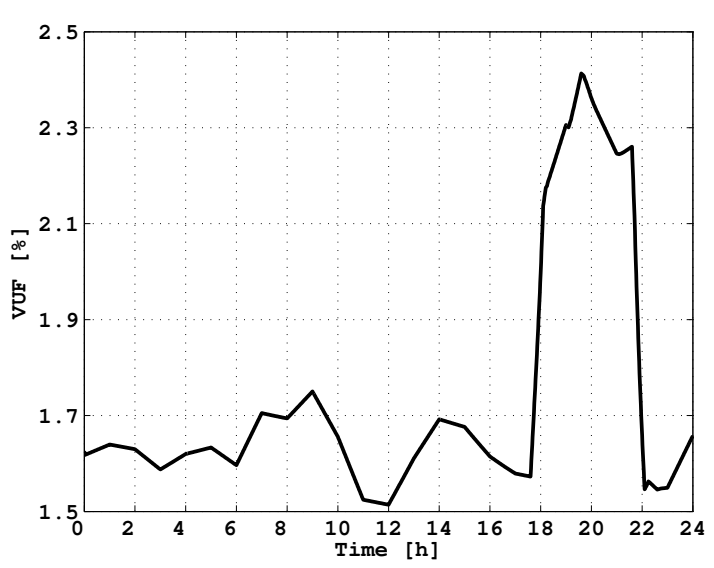

(b)

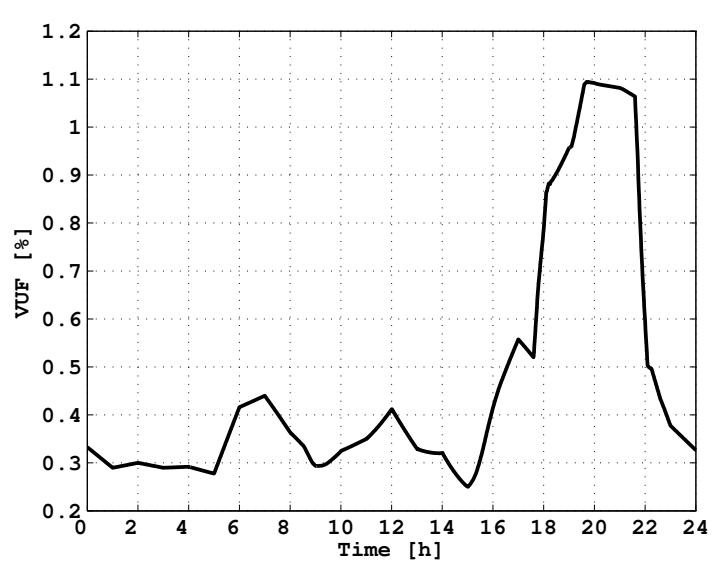

(d)

Figure 4. Base case - (a) Voltage profile in node 613, winter scenario - (b) Voltage imbalance factor in node 613, winter scenario - (c) Voltage profile in node 613, spring scenario - (d) Voltage imbalance factor in node 613, spring scenario

regulation when they inject active power. Considering that the grid has $X / R$ ratio of 2.85 hence, the reactive contribution to voltage regulation has a minimal impact to voltage magnitude. In addition, the control can only operate in presence of an active power injection and therefore, it does not work in case of low solar radiation. Voltage unbalance factor (VUF) [9] has been used as a key index parameter for measuring the grid imbalance grade. It has been defined by IEEE Std 1159 as the ratio between the negative-sequence voltage magnitude and the positive-sequence voltage magnitude [10]:

$$
V U F=\frac{V_{n}}{V_{p}} \cdot 100 \% .
$$

IEEE Std 1159 states that if the grid is characterized by a VUF higher than $2 \%$ the grid imbalance grade is unacceptable [10].

\section{A. Electric vehicles charging profile.}

The charging profile used for the EV charge is called "dumb charge". This profile, shown in Fig. 5, has been considered significant for the study because in Denmark is considered the worst EV charge profile [11]. According to this profile, the charge starts at 18:00 and last for 5 hours with a total consumption of $14.3 \mathrm{kWh}$. During the first hour, the vehicle absorbs $3 \mathrm{kWh}$. In the following three hours, $3.7 \mathrm{kWh}$ per hour are absorbed and during the last hour the consumption is $0.2 \mathrm{kWh}$. In addition, converter's reactive power absorption has been neglected. The charge is performed during the evening peak-consumption hours.

\section{RESUlts}

In both scenarios are present $27 \mathrm{PV}$ spread in the observed grid. As said, to each of the $\mathrm{PV}$ has been added a reactive power control as in [7] done. The control inject or absorb reactive power according to the phase-neutral voltage measure and the active injection. The PV active injection in the winter scenario can be neglect. Therefore the RPC do not provide any voltage regulation. In the spring scenario the active injection is equal to $3096.20 \mathrm{kWh}$ between 07:00 and 21:00. Therefore, the RPCs regulate the voltage by the reactive injection absorption. The RPCs prevent over voltage in phases B and 


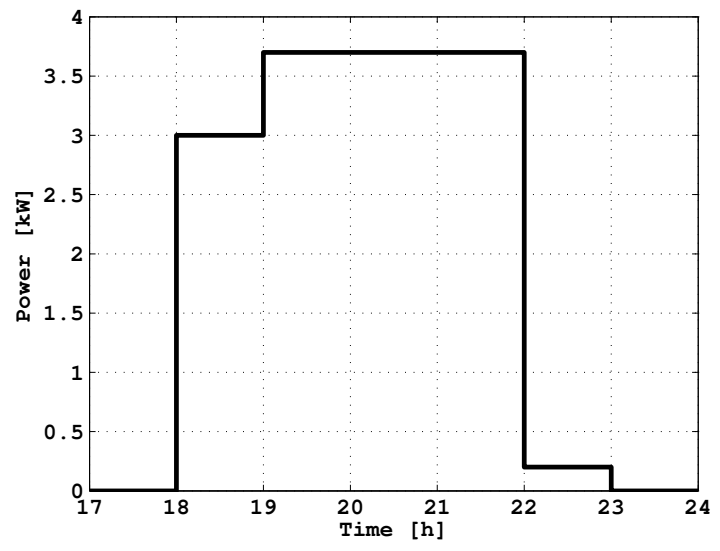

Figure 5. Electric vehicles - dumb charge profile

$\mathrm{C}$ maintain the voltage magnitude inside the non-regulation band above 1.02p.u., this can be noted in the voltage profiles reported in Fig.4(c) and Fig.6(c). The PVs production ends at 21:00 therefore, the installations contribute only in the initial part to the vehicles charge. In the base case scenario, EVs have been integrated installing the converters randomly on the three phases. Therefore, the overall absorption is equally distributed among the three phases. Figure 4(a) reports the voltage profiles in node 613 during the winter scenario. In this case the phase A voltage magnitude is close to 0.90 p.u. when the EVs are not connected. Between 18:00 and 20:00 voltage drops reaching a magnitude of $0.82 \mathrm{p} . \mathrm{u}$., which is the lowest voltage value during the day. The voltage sag is caused by the EVs charge. voltage magnitude of phases B and $\mathrm{C}$ are around 0.98 p.u. before the EVs charge. They reach the lowest value between 20:00 and 22:00 when their value drops to a value slightly higher than 0.92 p.u.. Figure 4(b) reports VUF profile during the winter scenario in node 613. As long as no EVs are connected, VUF has a value between $1.75 \%$ and $1.50 \%$, remaining above the threshold of $2 \%$. When EVs start their charge, VUF profile starts to increase and

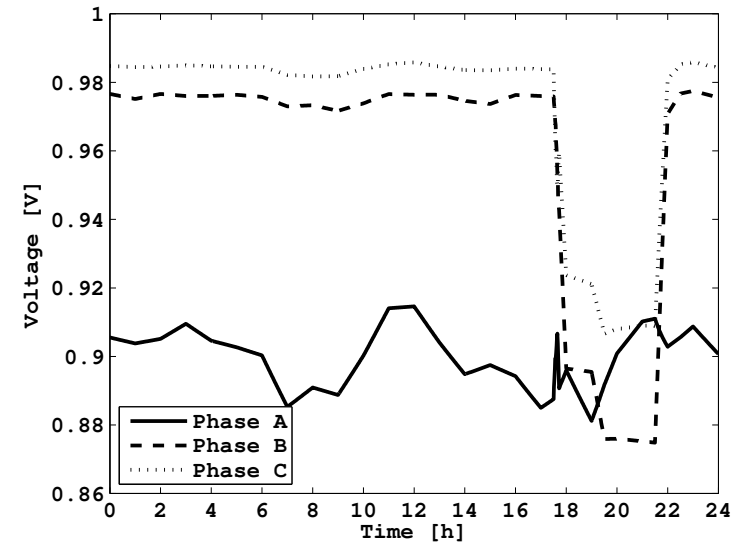

(a)

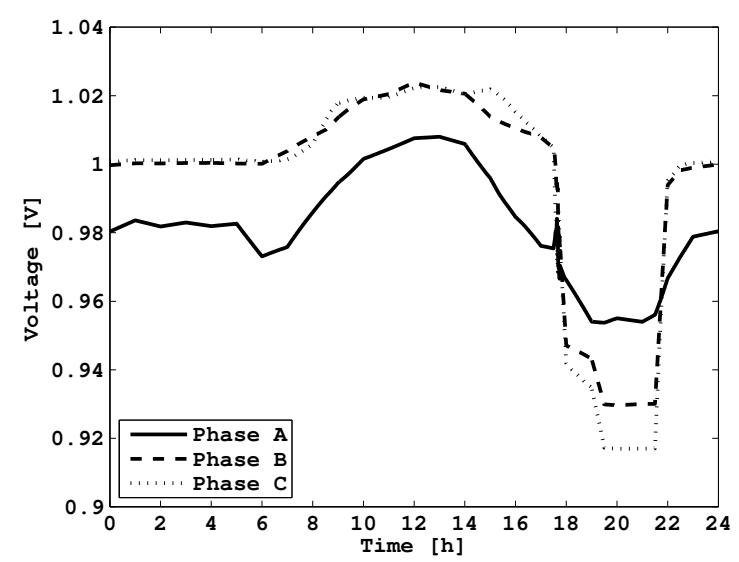

(c)

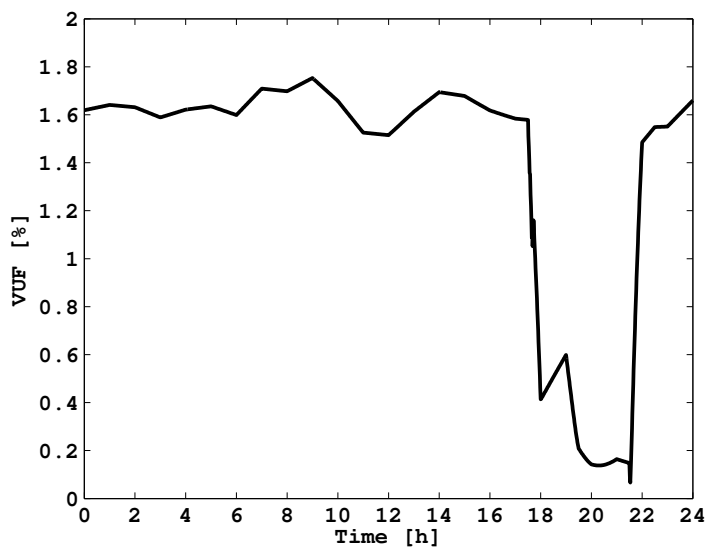

(b)

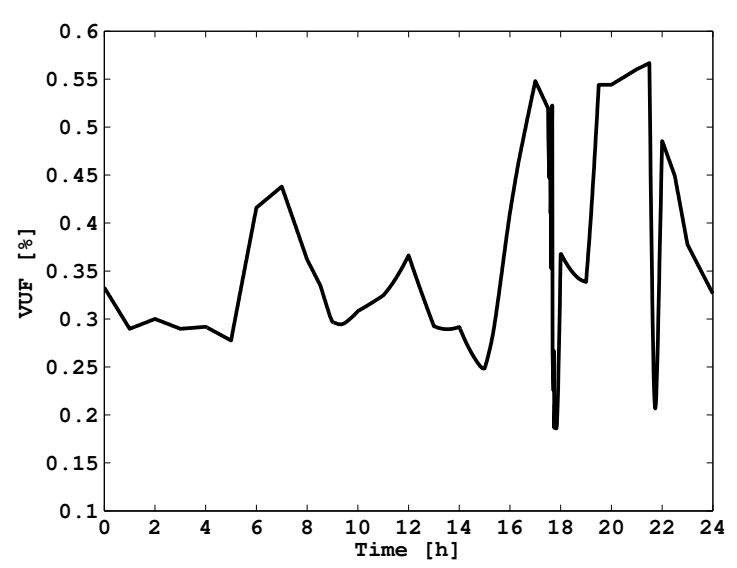

(d)

Figure 6. Control strategy active - (a) Voltage profile in node 613, winter scenario - (b) Voltage imbalance factor in node 613, winter scenario - (c) Voltage profile in node 613, spring scenario - (d) Voltage imbalance factor in node 613, spring scenario 
goes over the upper limit of $2 \%$. In the winter scenario, the lower voltage limit of $-10 \%$ and the upper VUF bound of $2 \%$ have been exceeded. Therefore, this situation cannot be accepted. Figure 4(c) and Fig. 4(d) report voltage and VUF profiles at node 613 during the spring scenario. It can be noted that the voltage drop, caused by EVs charge, does not exceed the lower limit. Phase A drops down to 0.92 p.u. while the other two phases are always over 0.96 p.u.. For this reason, VUF does not exceed the upper limit. During EVs charge VUF is always lower than $1 \%$. In both scenarios, voltage sag is almost equal for the three phases because EVs are equally distributed among the phases. The designed control is able to perform a balancing action shuffling EVs among the phases according to voltage magnitude measurements. As a consequence, load should be more equally distributed. The results from the control strategy are reported in Fig. 6. In Fig. 6(a) and Fig. 6(b) voltage and VUF profiles at node 613 are plotted during the winter scenario. In Fig. 6(c) and Fig. 6(d) voltage and VUF profiles for the spring scenario are reported. In the winter scenario the great majority of the $\mathrm{EVs}$ is connected to phase $\mathrm{B}$, whose voltage drops to 0.88 p.u. between 20:00 and 22:00. The remaining part of the EVs choose phase $\mathrm{C}$, whose voltage goes to 0.91 p.u. during EVs charge. Phase A has not been chosen by any EV because it is the most loaded phase. This is confirmed comparing phase A and phase B magnitude between 18:00 and 19:00. From the comparison it can be noted that phase A is always lower than phases $\mathrm{B}$ and $\mathrm{C}$. For this reason the control never selects this phase. The balancing action is confirmed by Fig. 6(b): VUF profile decreases when EVs start their charge reaching the lowest limit of $0.18 \%$ between 20:00 and 21:00. In the spring scenario, the great majority of EVs chooses phases $\mathrm{C}$ which displays the greatest voltage drop. In the spring scenario the voltage magnitudes do not exceed the lower bound and if those profiles are compared with the profiles reported in the uncontrolled case (see Fig. 4(c)) it evident that the voltage sag caused by the EVs charge is lower for all the phases. In addition, the lowest voltage magnitude is 0.92 p.u. (with respect to a figure of 0.90 p.u. in the uncontrolled case). The balancing action is "less important" during the spring scenario than in the winter scenario. Figure 6(d) shows that VUF, during EVs charge, is kept below $0.55 \%$.

\section{Conclusion}

EVs charge will gravely affect future distribution network. In this paper the opportunity to use EVs in order to balance an imbalance grid has been investigated. This action has been performed enabling the phase selection of the charging spot. Moreover, a time check has been added. This avoids the case where all the charging spots request power simultaneously on the same phase. A timestamp of 15 minutes has been assigned to each of the charging spot in order to coordinate the request of power with the OLTC intra-day scheduling. Moreover, 15 minutes can also be considered an acceptable delay between the plug-in and the charging start from a commercial point of view. The control strategy designed has been tested with success in a winter scenario and in a spring scenario over a real Danish low voltage network using real consumption and production measurement. Therefore, it is possible to infer that a better EVs distribution among the phases thanks to this control strategy allow to perform a balancing action. This is witness by the VUF sag due to the control strategy action. Therefore, EVs can be use in order to balance a distribution grid becoming an important resource.

\section{REFERENCES}

[1] M. Coppo, R. Turri, M. Marinelli, and X. Han, "Voltage Management in Unbalanced Low Voltage Networks Using a Decoupled PhaseTap-Changer Transformer," in Proceedings of the 49th International Universities Power Engineering Conference (UPEC), 2014, pp. 1-6.

[2] F. Baccino, S. Massucco, F. Silvestro, and S. Grillo, "Management strategy for unbalanced LV distribution network with electric vehicles, heat pumps and domestic photovoltaic penetration," in PES General Meeting Conference Exposition, 2014, pp. 1-5.

[3] AA.VV., "Scenarios for the deployment of electric vehicles," Dansk Energi, Tech. Rep., 2013.

[4] DIgSILENT GmbH - PowerFactory 15.0 User Manual, Gomaringen, Germany.

[5] P. Lico, "Unbalance analysis of a real low voltage Danish network with presence of electric vehicles and small size photovoltaic plants," Master's thesis, Politecnico di Milano, 2013/2014.

[6] F. Adinolfi, F. Baccino, M. Marinelli, S. Massucco, and F. Silvestro, "Model of a Real Medium Voltage Distribution Network for Analysis of Distributed Generation Penetration in a SmartGrid Scenario," in 3rd IEEE PES Innovative Smart Grid Technology Europe, 2012, pp. 1-7.

[7] K. Knezovic, M. Marinelli, R. Moller, P. Andersen, C. Traholt, and F. Sossan, "Analysis of voltage support by electric vehicles and photovoltaic in a real Danish low voltage network," in Power Engineering Conference (UPEC), 2014, pp. 1-6.

[8] Regola tecnica di riferimento per la connessione di Utenti attivi e passivi alle reti BT delle imprese distributrici di energia elettrica (Reference technical rules for the connection of active and passive users to the $L V$ electrical Utilities), CEI Std. 0-21, Sep. 2014, in italian.

[9] Electromagnetic compatibility (EMC) - Part 4-30: Testing and measurement techniques - Power quality measurement methods, IEC Std. 61 0004-30:2015.

[10] IEEE Recommended Practice for Monitoring Electric Power Quality, IEEE Std. 1159, 2009.

[11] P. Bach Andersen, "Intelligent Electric Vehicle Integration - Domain Interfaces and Supporting Informatics," Ph.D. dissertation, Technical University of Denmark, 2013. 